\title{
Falando sobre a Mente: Algumas Considerações sobre a Relação entre Linguagem e Teoria da Mente
}

\author{
Speaking About the Mind: Some Thoughts on the Relation \\ Between Language and Theory of Mind \\ Débora de Hollanda Souza* \\ Universidade Federal de São Carlos, São Carlos, Brasil
}

\begin{abstract}
Resumo
A pesquisa sobre a aquisição da teoria da mente tem obtido grandes avanços nas últimas décadas, mas ainda há muito a ser desvendado, principalmente no que concerne os mecanismos subjacentes ao desenvolvimento desta teoria. Pesquisas recentes têm investigado a possível relação entre linguagem e teoria da mente e vários estudos têm sido conduzidos em diversas comunidades lingüísticas. O presente trabalho visa apresentar, portanto, as diferentes posições sobre a relação entre linguagem e teoria da mente assim como destacar a importância da realização de estudos transculturais. Além disso, pretende-se apontar caminhos interessantes para a pesquisa em teoria da mente no Brasil.
\end{abstract}

Palavras-chave: Linguagem; teoria da mente; estudos transculturais.

\begin{abstract}
Research on theory of mind development has made important advances in the last two decades, however, there is much to be unveiled, particularly regarding the mechanisms underlying this aspect of development. Recent research has investigated a possible relationship between language and theory of mind and several studies have been conducted in different linguistic communities. The work presented here is aimed, therefore, at presenting different theoretical accounts of the relationship between language and theory of mind and reinforcing the importance of cross-linguistic studies. Moreover, this work is aimed at pointing to interesting directions for research on theory of mind in Brazil.

Keywords: Language; theory of mind; cross-linguistic studies.
\end{abstract}

Um marco importante do desenvolvimento cognitivo é a aquisição de uma teoria da mente, ou seja, a habilidade para explicar e predizer o comportamento humano através de fenômenos mentais (intenções, crenças e emoções). É esta teoria que nos permite, por exemplo, compreender que alguém pode ter crenças falsas, que pode ser enganado, que pode ter pensamentos e idéias diferentes dos de uma outra pessoa, pensamentos e idéias que podem contradizer a realidade.

Durante as últimas duas décadas, um número crescente de pesquisas tem contribuído para uma melhor compreensão de como e quando as crianças desenvolvem essa teoria (e.g., Astington, Harris, \& Olson, 1988; Dias, 1993; Flavell, Flavell, \& Green, 1983; Frye, \& Moore, 1991; Wellman, 1990; Wimmer, \& Pemmer, 1983); entretanto, um consenso sobre quais fatores contribuem definitivamente para o desenvolvimento da teoria da mente ainda não foi alcançado.

\footnotetext{
* Endereço para correspondência: Rua Orlando Damiano, 2100, apto. 162, Jardim Macarengo, São Carlos, SP, 13.560-450. Fones: (16) 3371-9534 ou (11) 4586-8135; Fax: (11) 4522-2760. E-mail: debhsouza@uol.com.br

Parte da revisão da literatura apresentada neste trabalho foi realizada durante o curso de doutorado da autora na Universidade do Texas e recebeu o apoio do Conselho Nacional de Desenvolvimento Científico e Tecnológico - CNPq.

A autora agradece ao $\mathrm{CNPq}$, à Cláudia Cardoso-Martins pelos comentários e apoio, e à Catharine Echols pelo excelente trabalho de orientação.
}

Mais recentemente, vários pesquisadores têm demonstrado interesse em investigar a relação entre linguagem e teoria da mente (Astington, 2001; Astington \& Jenkins, 1999; de Villiers \& de Villiers, 2000, 2003; Jenkins \& Astington, 1996; Shatz, 1994). Uma investigação da linguagem que as crianças utilizam para se referir a estados mentais poderia, a princípio, revelar dados importantes a respeito do processo de aquisição de uma teoria da mente. Entretanto, ainda há divergências sobre o papel da linguagem, ou mais precisamente, sobre quais aspectos da teoria da mente são influenciados pela linguagem e de que forma essa influência é exercida.

Alguns pesquisadores afirmam que a linguagem pode exercer um papel importante e específico no desenvolvimento da teoria da mente (Astington, 2001; Astington \& Jenkins, 1999; de Villiers \& de Villiers, 2000); deste grupo, alguns defendem uma versão mais radical (de Villiers \& de Villiers, 2003), argumentando que a compreensão da crença falsa, evidenciada mediante a aplicação de tarefas específicas de crença falsa, depende da linguagem. Outros investigadores são mais cautelosos e sugerem que mais estudos analisando a natureza exata da relação entre linguagem e teoria da mente sejam necessários (Shatz, 1994; Shatz, Diesendruck, Martinez-Beck \& Akar, 2003). Diante de tais 
divergências, é necessário, portanto, que se faça uma avaliação das contribuições destes estudos, estabelecendo-se assim novas frentes possíveis de trabalho.

O presente artigo tem como objetivo fornecer uma revisão da literatura sobre o tema, apresentando as diferentes posições sobre a relação entre linguagem e teoria da mente. Um segundo objetivo é o de sugerir que estudos transculturais possam trazer contribuições importantes para o debate atual entre os pesquisadores interessados na relação entre linguagem e a cognição, em geral. Finalmente, este artigo visa apontar caminhos interessantes para a pesquisa sobre a teoria da mente no Brasil e destacar a importância de se conduzir estudos com falantes de línguas como o português.

\section{Falando e Teorizando sobre a Mente}

Uma dos sinais de que uma criança possui uma teoria da mente é a compreensão de que outras pessoas podem ter uma crença falsa, ou seja, de que alguém pode ter um pensamento ou uma crença que não condiz com a realidade. Esta compreensão é testada através do método que convencionalmente tem sido chamado de tarefa da crença falsa. Há, na verdade, várias versões desta tarefa. Em uma delas, a do conteúdo inesperado, o objetivo é testar crianças em sua capacidade de compreender uma mudança representacional, ou seja, de compreender que é possível se modificar idéias ou crenças a respeito do mundo. Gopnik e Astington (1988), por exemplo, testaram essa capacidade em crianças entre 3 e 5 anos de idade. Em uma das tarefas utilizadas neste estudo, uma caixa de chocolates é apresentada à criança. Pergunta-se à criança então o que está dentro da caixa e depois se mostra que, na verdade, a caixa contém algo diferente, como por exemplo, um conjunto de canetas. Quando se pergunta às crianças com menos de 4 anos o que elas pensavam que estava na caixa anteriormente (antes de se abrir a caixa), elas insistem em afirmar que sabiam que a caixa tinha canetas. Estes resultados indicam, portanto, que as crianças mais novas não conseguem compreender que a sua representação sobre o conteúdo da caixa pode ser modificada. Além disso, elas dizem que outras pessoas seriam capazes de prever que existem canetas dentro da caixa, mesmo que não tenham visto o que está lá dentro, sugerindo que elas não conseguem atribuir uma crença falsa à uma terceira pessoa.

Outra versão teve origem na chamada tarefa de Maxi, procedimento utilizado no estudo que praticamente iniciou este campo de estudo (Wimmer \& Perner, 1983). Neste estudo, 36 crianças entre 3 e 9 anos de idade ouviram a seguinte estória: Maxi, o protagonista, guarda um chocolate em um local (A). Enquanto ele sai para brincar, a mãe muda o chocolate para um outro local (B). O experimentador então pergunta à criança "Quando Maxi voltar, aonde ele irá procurar pelo chocolate?” Para que uma criança tenha sucesso nesta tarefa, é preciso que ela reconheça que há uma contradição entre a atual e verdadeira localização do chocolate e a localização do chocolate quando Maxi o viu pela última vez. Os resultados de Wimmer e Perner (1983) revelaram que as crianças de 3 e 4 anos consistentemente respondem que Maxi irá procurar o chocolate no local B, mesmo sabendo que Maxi não testemunhou a mudança de local. Mais especificamente, nenhuma das crianças no grupo de 3 a 4 anos forneceu a resposta correta, enquanto $57 \%$ das crianças de 4 a 6 anos e $86 \%$ das crianças no grupo de 6 a 9 anos apontaram corretamente para o local correto (A). Estes dados sugerem que, antes de 4 anos de idade, as crianças têm dificuldade em atribuir uma crença falsa a outras pessoas e a elas próprias.

Outros estudos realizados nas últimas duas décadas parecem confirmar que as crianças só conseguem obter sucesso nesse tipo de tarefa a partir dos 4 anos (e.g., Astington, \& Gopnik, 1991; Perner, Leekam, \& Wimmer, 1987), mas uma pergunta permanece: como as crianças desenvolvem uma compreensão da crença falsa, ou melhor, como elas adquirem uma teoria da mente? Há evidências, no entanto, de que certas habilidades lingüísticas estão fortemente correlacionadas com o raciocínio sobre a crença falsa e, conseqüentemente, com o desenvolvimento da teoria da mente (Cutting \& Dunn, 1999; Farrar \& Maag, 2002; Happé, 1995; Jenkins \& Astington, 1996).

Happé (1995), por exemplo, demonstrou que o sucesso na tarefa de crença falsa está significativamente correlacionado com o vocabulário receptivo medido pelo British Picture Vocabulary Scale (BPVS). Além disso, indivíduos com autismo precisam de um nível mais elevado de habilidade verbal do que crianças com desenvolvimento típico para que possam passar nas tarefas de crença falsa (Happé, 1995). Jenkins e Astington (1996), por sua vez, utilizaram o Test of Early Language Development (TELD) para fornecer uma medida de habilidade sintática e semântica em crianças entre 2 e 5 anos de idade e uma medida de memória de sentenças do Stanford-Binet para avaliar a memória verbal. O sucesso em tarefas de crença falsa foi correlacionado significativamente com a habilidade lingüística geral dessas crianças e sua memória verbal.

Estudos com populações especiais também parecem reforçar a hipótese de uma relação significativa entre linguagem e teoria da mente, ou seja, de que o desenvolvimento de uma teoria da mente é intrinsicamente relacionado com a aquisição de habilidades lingüísticas. Os resultados de Peterson e Siegal (1998), por exemplo, apontaram algumas semelhanças entre crianças autistas e crianças surdas, cujos pais têm audição normal, no desenvolvimento da teoria da mente. Os dois grupos tiveram desempenho significativamente pior em tarefas de crença falsa do que crianças de 4 anos com desenvolvimento típico. Peterson e Siegal argumentam que essa semelhança provém de uma realidade compartilhada por esses dois grupos de crianças: ambos são privados de conversas sobre fenômenos mentais no início do desenvolvimento.

Crianças surdas, cujos pais têm audição normal, tendem a receber um input lingüístico limitado, particularmente se essas crianças estão sendo treinadas oralmente ${ }^{1}$. Além disso,

\footnotetext{
${ }^{1}$ Muitos pais que possuem audição normal, mas cujos filhos apresentam grande perda auditiva, querem que estes aprendam a língua falada em seu país e a leitura labial. Avanços tecnológicos têm contribuído com aparelhos que proporcionam um ganho auditivo significativo e muitas crianças têm acesso a um treinamento especial; entretanto, a maioria delas ainda apresenta um atraso no desenvolvimento da linguagem oral em relação às crianças de audição normal.
} 
as poucas palavras que elas adquirem provavelmente se referem a coisas concretas. Em relação às crianças autistas, o argumento é o de que as dificuldades enfrentadas no domínio social assim como suas habilidades pragmáticas limitadas podem contribuir para um número reduzido de conversas sobre estados mentais, como desejos, intenções e emoções implícitos no desenvolvimento da teoria da mente. Esta é uma hipótese corroborada por resultados prévios obtidos por Judy Dunn, Brown e Beardsall (1991), indicando que as conversas familiares sobre emoções no início da vida estão correlacionadas com a habilidade das crianças em reconhecer emoções aos 6 anos de idade.

Mais recentemente, Cicchetti, Rogsch, Maughan, Toth, e Bruce (2003) argumentaram que se pode encontrar evidências da relação entre conversas familiares e teoria da mente em um outro tipo de população especial: crianças vítimas de abuso. Este estudo foi realizado com 518 crianças entre $3 \mathrm{e}$ 8 anos de idade divididas em três grupos: (a) crianças vítimas de maus tratos; (b) crianças de nível sócio-econômico baixo que não sofrem de maus tratos; e (c) crianças de nível sócio-econômico médio que não sofrem de maus tratos. Duas tarefas de crença falsa foram administradas envolvendo a situação do conteúdo inesperado (Gopnik \& Astington, 1988; Perner et al., 1987). Os resultados deste estudo indicaram uma correlação significativa entre maus tratos e atrasos no desenvolvimento da teoria da mente. De fato, um número significativamente menor de crianças vítimas de maus tratos teve sucesso nas tarefas de crença falsa (56,3\%), enquanto 71, 3 \% das crianças de nível sócio-econômico baixo e 78,1 \% das crianças de nível sócio-econômico médio (ambos os grupos sem maus tratos) obtiveram sucesso nas tarefas. Uma possível explicação para tal correlação é a de que os pais de crianças vítimas de abuso tendem a reconhecer com freqüência menor as experiências internas de seus filhos devido a uma sensibilidade restrita e níveis reduzidos de empatia com seus filhos. Conseqüentemente, essas crianças podem também estar sendo privadas de uma linguagem que promove o desenvolvimento de uma teoria da mente. Embora esse argumento seja interessante, é necessário que mais pesquisas investigando o conteúdo das interações verbais nessas famílias sejam realizadas.

\section{O Papel da Sintaxe no Desenvolvimento da Teoria da Mente}

Outros pesquisadores, no entanto, têm se dedicado a outros aspectos lingüísticos do desenvolvimento da teoria da mente. Por exemplo, de Villiers e de Villiers (2000) estão interessados no papel da sintaxe. Eles argumentam que a sintaxe de complementação é um pré-requisito importante para a aquisição de uma teoria da mente (de Villiers \& de Villiers, 2000; 2003). Algumas sentenças em inglês, como as que incluem estados mentais, exigem um complemento. Por exemplo, a sentença "I think he's coming for dinner" [Eu acho que ele vem para o jantar] inclui o verbo de estado mental "think" [acho] que exige um complemento, uma oração subordinada: "he's coming for dinner" [que ele vem para o jantar], neste caso. Através do uso de complementos, pode-se expressar uma crença que pode, na verdade, ser diferente da crença de uma outra pessoa ou mesmo da realidade.

Como evidência, de Villiers e de Villiers (2000) apresentaram os resultados de um estudo longitudinal com crianças entre 3 e 4 anos de idade. Três diferentes tarefas de crença falsa foram utilizadas: a tarefa de conteúdo inesperado, uma adaptação da tarefa de Wimmer e Perner (1983), durante a qual um objeto é deslocado sem que um terceiro personagem presencie a mudança de local, e uma tarefa que é a combinação das duas primeiras. Os participantes foram avaliados também quanto a sua memória e produção de complementos sentenciais. Por exemplo, em um dos testes, o experimentador contava uma estória e dizia à criança "Ele (o personagem da estória) pensou que tinha achado o seu anel mas, na verdade, era uma tampa de garrafa. O que ele pensou?" O participante, portanto, devia produzir uma oração principal que continha um verbo de crença (pensar) que, por sua vez, exigia uma oração subordinada ("que tinha achado o seu anel”), exprimindo, dessa forma, uma crença falsa. Segundo de Villiers e de Villiers (2000), sem o domínio dessa estrutura sintática, as crianças não conseguem ter sucesso em tarefas de crença falsa. O melhor preditor para o sucesso nas tarefas de crença falsa foi a capacidade de produzir complementos sentenciais $(47 \%$ da variância, $p<.001$ ).

Além disso, de Villiers e de Villiers (2000) forneceram dados empíricos com crianças surdas sugerindo que estas apresentam atrasos significativos em dois tipos diferentes de tarefas de crença falsa. Em uma tarefa denominada o jogo do adesivo [sticker-finding game], 23 crianças surdas (de 4 a 9 anos de idade) tiveram que encontrar um adesivo escondido pelo experimentador em uma de várias caixas. Elas receberam pistas de um ajudante do experimentador (que tinha os olhos vendados quando o adesivo foi escondido) e do próprio experimentador que sabia aonde o adesivo se encontrava. Somente $47.8 \%$ das crianças surdas, que foram treinadas oralmente, escolheram a caixa para a qual o experimentador (que de fato sabia a localização do adesivo) tinha apontado com uma freqüência maior do que seria esperado pelo acaso. Além disso, a idade média das crianças surdas que tiveram sucesso nesta tarefa era de 7.31 anos.

Em outra tarefa (o jogo chamado Qual Rosto?), outro grupo de crianças com grande perda auditiva (de 5:2 a 10:1 anos de idade) observou uma sequiência de gravuras. Na primeira gravura, o personagem principal manipulava um objeto, por exemplo, uma chave. Em uma das duas versões da estória (a de não surpresa), um amigo do personagem principal o observava removendo o conteúdo de um recipiente familiar (e.g., uma caixa de giz de cera) e colocando o objeto da primeira gravura (a chave) neste recipiente. Na outra versão (surpresa), o personagem principal realizava a mesma ação de colocar um conteúdo inesperado em um recipiente familiar, mas sem que o amigo soubesse ou testemunhasse a mudança de conteúdo do recipiente familiar. Na última gravura, o amigo abria o recipiente. $\mathrm{O}$ experimentador pedia aos participantes que respondessem se o personagem ficaria surpreso ou não ao verificar o que o recipiente continha. 
Os participantes forneciam a resposta ao escolherem a gravura mostrando o rosto com a expressão facial correta (surpresa ou neutra) e o colocando no rosto em branco do personagem.

Surpreendentemente, apenas $32 \%$ dos participantes obtiveram sucesso nessa tarefa, o que parecia indicar que essa tarefa menos verbal era ainda mais difícil para as crianças surdas do que a tarefa verbal. É importante observar que o desempenho das crianças com audição normal na tarefa verbal estava correlacionado significativamente com o desempenho delas na tarefa menos verbal Qual Rosto? $(r(26)=$ $+.61, p<.001)$. Além disso, o melhor preditor de sucesso para as crianças surdas em ambas tarefas foi a habilidade de compreender e produzir a sintaxe de complementação. Em resumo, de Villiers e de Villiers (2000) argumentam que as crianças surdas tendem a ter dificuldades com a tarefa de crença falsa antes de adquirirem a sintaxe de complementação, sugerindo assim que é a linguagem que determina o sucesso na tarefa de crença falsa.

\section{A Aquisição de Palauras Referentes à Mente}

Há ainda um outro grupo de pesquisadores que tem se interessado em analisar o papel desempenhado pela semântica e pela aquisição de palavras que se referem a estados mentais no desenvolvimento da teoria da mente. Por exemplo, Moore, Pure e Furrow (1990) contribuíram com dados interessantes demonstrando que a competência das crianças com verbos que expressam diferentes níveis de certeza como achar e saber está correlacionada com o desempenho em tarefas que testam a teoria da mente.

Bartsch e Wellman (1995) trouxeram também uma contribuição inestimável para o campo, pois foram os primeiros a tentar identificar em que ponto do desenvolvimento infantil as crianças começam a incorporar termos mentais ao seu vocabulário produtivo. O banco de dados CHILDES (Child Language Data Exchange System) foi utilizado para realizar tal tarefa. O que a análise desses dados revelou é que as crianças adquirem palavras referentes a desejos (e.g., querer, desejar) antes de palavras que se referem a crenças (e.g., pensar, achar, e saber). Segundo Bartsch e Wellman (1995), por volta dos 3 anos de idade, as crianças começam a conversar sobre pensamentos e crenças; em seguida, são capazes de fazer conexões entre esses pensamentos e crenças e a sua compreensão da mente e comportamento humanos, construindo assim uma teoria da mente.

É possível que todos esses diferentes aspectos da linguagem exerçam um papel no desenvolvimento de uma teoria da mente. Entretanto, o que permanece problemático é que a maioria dos estudos investigando essa relação fornece apenas dados correlacionais e, além disso, a maioria deles utiliza a tarefa de crença falsa como se esta fosse a única medida da teoria da mente. Diante das evidências atuais, afirmações sobre uma relação causal entre linguagem e teoria da mente são inapropriadas assim como afirmações sobre a direção dessa relação. Além disso, ainda pouco se sabe sobre a universalidade do processo de aquisição da teoria da mente. Estudos trans-culturais podem apontar impor- tantes influências lingüísticas e culturais no desenvolvimento de uma compreensão da mente.

\section{Linguas Diferentes, Teorias Diferentes?}

A questão que deve ser levantada é a seguinte: crianças de culturas e línguas diferentes seguem o mesmo padrão de desenvolvimento em direção a uma teoria da mente? Mais especificamente, será que diferenças na forma como diferentes línguas expressam estados mentais podem ter efeitos na compreensão infantil do mundo mental e, possivelmente, no período de tempo durante o qual elas adquirem uma teoria da mente? Apesar de estudos recentes terem revelado dados interessantes, ainda há muito a ser descoberto.

Por exemplo, Lee, Olson e Torrance (1999) se interessaram em investigar possíveis diferenças entre crianças falantes do chinês e do inglês no desempenho em tarefas de crença falsa. Uma característica importante do chinês é a de que esta língua possui verbos que explicitamente denotam "pensar algo verdadeiro" e verbos que denotam "pensar algo falso." O objetivo de Lee et al. era o de testar o efeito dessa diferença lingüística particular no desempenho de crianças de 3, 4 e 5 anos de idade na tarefa de crença falsa.

Os participantes foram designados para uma dentre três condições. Cada condição consistia nas mesmas três tarefas de crença falsa: uma tarefa de conteúdo inesperado, uma variação da tarefa de Maxi (Wimmer \& Perner, 1983) e uma adaptação da tarefa de aparência-realidade (Flavell et al., 1983). Nesta última, o experimentador lia uma estória ilustrada sobre uma gata que leva seus filhos para um piquenique. A gata mãe vê uma tartaruga que se parece com uma pedra e, por engano, coloca a comida e os pratos nas costas da tartaruga. $\mathrm{O}$ experimentador então apontava para a tartaruga e fazia 3 perguntas: (a) "O que é isso?"; (b) "A gata mãe sabe que isso é uma tartaruga?"; e (c) "O que a mãe acha que isso é?” A única diferença entre as três condições se relacionava ao verbo mental utilizado na terceira pergunta. $\mathrm{O}$ verbo xiang é considerado mais neutro e pode ser traduzido como pensar ou crer (acreditar). Yiwei, por outro lado, indica que uma crença pode ser falsa. Dang se aplica literalmente a situações em que uma crença falsa está presente.

Os resultados dessa pesquisa indicaram que as crianças falantes do chinês parecem seguir o mesmo padrão de desenvolvimento de uma compreensão da crença falsa que as crianças ocidentais, ou seja, o sucesso nas tarefas de crença falsa tende a aumentar significativamente entre os 3 e 5 anos de idade. Entretanto, o desempenho nas tarefas de crença falsa é afetado pelo uso dos diferentes verbos referentes à crença. Os participantes tiveram um desempenho significativamente melhor quando os verbos yiwei e dang foram utilizados, sugerindo que a capacidade para realizar tarefas de crença falsa pode ser influenciada pela linguagem utilizada durante o experimento.

Mais recentemente, Shatz et al. (2003) realizaram comparações interessantes entre falantes de quatro línguas: turco, espanhol de Porto Rico, português brasileiro e inglês. Enquanto o turco e o espanhol de Porto Rico têm termos 
explícitos para denotar a crença falsa (e.g., san em turco e creer-se no espanhol de Porto Rico que significam "pensar algo falso"), o inglês e o português brasileiro não possuem palavras que expressam explicitamente uma crença falsa.

Shatz et al. (2003) testaram crianças de 3 e 4 anos de idade em quatro tarefas de crença falsa. Duas delas eram versões da tarefa de Maxi (Wimmer \& Perner, 1983), feitas através da leitura de estórias. A estória sempre envolvia um personagem que deslocava um objeto sem que um segundo personagem presenciasse a mudança. As outras duas tarefas eram adaptações da tarefa do conteúdo inesperado envolvendo as próprias crianças e dois experimentadores. Em cada uma dessas tarefas, a criança respondia a quatro perguntas. Em uma tarefa envolvendo uma caixa de lápis de cera, por exemplo, a seguinte situação foi apresentada às crianças: Um dos experimentadores (E1) mostra à criança uma caixa de lápis de cera e uma caixa azul. Um outro experimentador (E2) diz que quer desenhar e vai buscar papel em outra sala. Após a saída de E2 da sala, E1 abre as duas caixas e mostra à criança que os lápis de cera estão, na verdade, na caixa azul e não na caixa de lápis de cera. E1 então faz duas perguntas à criança: (a) "Aonde (E2) acha que os lápis estão?" e (b) "Aonde (E2) irá procurar pelos lápis quando ele voltar?"

Metade das crianças falantes do espanhol de Porto Rico e das falantes do Turco ouviram a primeira pergunta marcada linguisticamente pelo termo que denota a crença falsa $($ san $\mathrm{e}$ creer-se) e metade delas ouviram a primeira pergunta com o termo neutro (diisiin em turco e creer em espanhol de Porto Rico). Estes dois grupos de crianças foram também comparados às crianças brasileiras e americanas, cujas línguas não marcam explicitamente a crença falsa. Portanto, as crianças falantes do português e do inglês ouviram a primeira pergunta sempre com os termos neutros: achar e think respectivamente.

Em um segundo momento, E2 retorna à sala, pega a caixa de lápis de cera e diz que não encontrou os papéis. E2 vai então para um canto da sala e começa a procurar papéis em sua bolsa. Duas outras perguntas são feitas com os objetivos de elicitar justificativas para o comportamento de E2: (c) "Por que (E2) pegou a caixa de lápis?", e (d) "Aonde os lápis estão na verdade?”.

Esse mesmo procedimento foi utilizado em uma outra tarefa envolvendo um conteúdo inesperado (um brinquedo Lego) com as mudanças devidas. Nas duas tarefas envolvendo estórias sobre um objeto deslocado, as quatro perguntas se referiam aos personagens das estórias e sobre o deslocamento de objetos e não sobre o conteúdo de um recipiente.

A presença de um termo explícito para denotar a crença falsa foi correlacionada com o desempenho superior nas respostas à primeira pergunta, ou seja, as crianças cujas línguas possuíam um termo explícito para a crença falsa responderam corretamente à primeira pergunta com uma frequiência maior do que as crianças cujas línguas só possuíam o termo neutro. De fato, $71 \%$ das crianças turcas e portoriquenhas tiveram um escore de 3 ou 4 (máximo de 4 pontos) na primeira pergunta, enquanto apenas $37 \%$ das crianças que não possuíam um termo explícito para a crença falsa em suas línguas obtiveram esse escore.

É importante ressaltar, entretanto, que essas diferenças só foram encontradas nas respostas à primeira pergunta, que inclui um termo específico para denotar uma crença, o achar. Nas respostas à segunda pergunta (e.g., "Aonde (E2) irá procurar pelo lápis quando ele voltar?"), nenhuma diferença significativa foi encontrada. Os resultados sugerem, portanto, que há um efeito do nível de explicitação lexical no desempenho em tarefas de crença falsa, mas este é um "efeito local." Portanto, Shatz et al. (2003) nos lembram que é preciso cautela ao se fazer afirmações sobre a natureza da relação entre linguagem e teoria da mente.

Outro estudo com crianças francesas (Bassano, 1985) investigou o desenvolvimento da compreensão do savoir (saber) e croire (crer). O experimentador apresentou às crianças quatro bonecas diferentes e cada uma delas tinha uma caixa que continha um objeto (um peixe ou um pássaro). A boneca $\mathrm{n}^{\mathrm{o}} 1$ tinha os seus olhos abertos e tinha um peixe dentro de sua caixa; a boneca $\mathrm{n}^{\circ} 2$ tinha os olhos vendados e tinha um pássaro em sua caixa; a boneca no 3 tinha os olhos abertos e possuía um pássaro; e finalmente, a boneca $\mathrm{n}^{\mathrm{o}} 4$ tinha os olhos vendados e um peixe em sua caixa. A tarefa consistia em indicar qual das bonecas iria dizer as seguintes afirmações: (a) "Eu sei que eu tenho um peixe", (b) "Eu sei que eu não tenho um peixe"; (c) "Eu não sei se eu tenho um peixe"; (d) "Eu creio que eu tenho um peixe".

Os resultados sugeriram que as crianças francesas de $4 \mathrm{e}$ 5 anos tem uma compreensão clara do savoir (saber) quando ele é utilizado na afirmativa, mas eles mostram algumas dificuldades com as sentenças negativas. Em particular, 60\% dos sujeitos não foram capazes de interpretar corretamente a frase "Eu sei que eu não tenho um peixe."

A confusão parecia derivar de uma tendência dessas crianças a interpretar a negação como estando ligada ao verbo saber, ou seja, elas interpretavam essa sentença como "Eu não sei se eu tenho um peixe." Outro dado interessante é o de que o desempenho das crianças com as sentenças incluindo achar era inferior ao desempenho delas com as sentenças incluindo saber. Bassano (1985) argumenta que a maioria das crianças de 4 e 5 anos tratam a palavra croire (crer) como tendo propriedades de certeza e é somente mais tarde que elas são capazes de perceber que o "achar" envolve um certo nível de indeterminação.

\section{A Pesquisa sobre Teoria da Mente no Brasil}

Apesar de estudos transculturais terem contribuído significativamente para uma maior compreensão sobre o processo de aquisição de palavras referentes a estados mentais, ainda há muito a ser desvendado. $\mathrm{O}$ conhecimento atual sobre esse processo de desenvolvimento em crianças falantes de várias línguas (não somente do inglês) ainda é limitado. No Brasil, o número de pesquisas também é pequeno. Alguns estudos, entretanto, foram realizados com o objetivo de se identificar se o período de aquisição de uma teoria da mente identificado em crianças americanas e européias 
(aproximadamente 4 anos) também se aplica a crianças brasileiras.

Por exemplo, Dias (1993) testou a compreensão da crença falsa em crianças brasileiras de orfanato assim como crianças de classe média e baixa usando adaptações de três tarefas da crença falsa. Apesar das crianças do orfanato terem tido um desempenho abaixo do esperado aos 4 e 5 anos, as crianças de classe média e baixa tiveram um desempenho acima do esperado pelo acaso nas três tarefas em todas as três idades (4, 5 e 6 anos). Esses resultados sugerem que as crianças brasileiras não diferem das americanas e européias no que concerne à tarefa da crença falsa (Baron-Cohen, Leslie \& Frith, 1985; Gopnik \& Astington, 1988; Wimmer \& Perner, 1983).

Em um outro estudo, Roazzi e Santana (1999) também testaram crianças brasileiras de 4 e 5 anos de idade em uma versão adaptada da tarefa da crença falsa. Três bonecas chamadas Tomatinha (com a cabeça em forma de tomate), Cenourinha (com a cabeça em forma de cenoura) e Bananinha (com a cabeça em forma de banana) foram apresentadas às crianças que participavam sempre em pares (uma participava com sujeito e a outra como parceiro). Um dos experimentadores $(\mathrm{E} 1)$ contava então às crianças que Tomatinha sempre trazia tomates para o lanche, Cenourinha trazia cenouras e Bananinha trazia bananas. Outro experimentador (E2) convidava o parceiro para levar as bonecas para o recreio. $\mathrm{O}$ E1 então sugeria à criança (sujeito) trocar o lanche da Bananinha por um chiclete. Em seguida, E1 fazia três perguntas: (a) "Qual é o tipo de lanche que (parceiro) pensa que Bananinha tem na lancheira?”; (b) "Qual o tipo de lanche que Bananinha pensa que tem na lancheira?"; e (c) "Qual o tipo de lanche que Bananinha tem na lancheira?”. As três perguntas foram também colocadas para as outras duas bonecas para testar a compreensão da tarefa por parte da criança.

Os resultados desse estudo, contudo, revelaram um padrão de desenvolvimento diferente do encontrado por Dias (1993). Somente $32 \%$ das crianças de 4 anos obtiveram sucesso na tarefa enquanto $98 \%$ das crianças de 5 anos demonstraram uma compreensão da crença falsa. Esses resultados poderiam ser interpretados como indicando um atraso no desenvolvimento da compreensão da crença falsa em crianças brasileiras. Entretanto, algumas variáveis intervenientes poderiam estar afetando os resultados de Roazzi e Santana (1999).

Eles utilizaram bonecas durante a tarefa porque um dos objetivos do estudo era testar se o uso de atores inanimados ou animados tem um efeito no desempenho das crianças nesta tarefa. Entretanto, as bonecas tinham uma aparência incomum (as cabeças em forma de tomate, cenoura ou banana). Pode-se levantar a hipótese de que estas bonecas eram tão atrativas paras as crianças que elas se tornaram uma distração, principalmente para as crianças mais novas. Este fato poderia também explicar porque os pesquisadores não conseguiram que as crianças de 3 anos participassem como eles tinham planejado originalmente. Segundo os autores, essas crianças não conseguiram manter um nível de atenção mínimo para a realização da tarefa. Uma outra possível explicação, levantada pelos próprios autores, é a de que as crianças de 4 anos possam ter se sentido inseguras quanto à resposta e, pensando se tratar de uma situação de exame, optaram por uma perspectiva que era a mais segura.

Mais recentemente, Jou e Sperb (2004) investigaram o desenvolvimento da teoria da mente em crianças de 3 a 5 anos utilizando três tarefas: uma tarefa de crença que avalia a habilidade da criança em predizer o comportamento de um personagem baseado em sua crença, uma versão da tarefa de crença falsa e uma tarefa de aparência-realidade. Nesta última tarefa, mostra-se à criança um objeto que tem a aparência de um outro (e.g., um imã de geladeira que parece um brigadeiro) e pergunta-se a ela sobre o quê os objetos parecem que são e o quê eles, na verdade, são. Cada tarefa é apresentada também em uma versão facilitada na tentativa de se obter um melhor desempenho dos participantes. Os resultados dessa pesquisa indicaram que não há diferenças significativas entre as crianças de 3 e 4 anos, mas há uma diferença significativa entre essas duas faixas etárias no desempenho na tarefa de crença falsa quando os grupos extremos (média de idade de 4 anos e 10 meses e de 3 anos e 4 meses) são comparados e quando as justificativas das crianças às suas respostas são levadas em consideração.

As autoras lembram, entretanto, que esses resultados não refletem uma divisão clara entre aqueles que possuem e aqueles que não possuem uma teoria da mente. Pelo contrário, há uma enorme variabilidade entre as crianças, o que parece indicar uma seqüência gradual em direção à aquisição da teoria da mente. Além disso, é sempre necessário se observar as condições experimentais uma vez que pequenas modificações na tarefa podem promover um desempenho melhor entre as crianças mais novas (Jou \& Sperb, 2004).

\section{Conclusão}

Inúmeras dificuldades são associadas às pesquisas transculturais e é provavelmente por essa razão que o número de estudos transculturais sobre o desenvolvimento de uma teoria da mente é ainda pequeno. Além de um custo mais elevado para se conduzir a pesquisa em mais de um país simultaneamente, há ainda a preocupação com fatores culturais que possam afetar os resultados. Apesar das dificuldades, se os pesquisadores interessados em teoria da mente quiserem estabelecer se a teoria da mente envolve um processo de desenvolvimento universal, é necessário que se conduza mais pesquisas em vários países, comparando-se assim diversas comunidades lingüísticas. Além disso, apesar da pesquisa em teoria da mente ter tido importantes avanços nas últimas duas décadas (cf. Astington, \& Baird, 2005), ainda há muito a ser revelado sobre a relação entre linguagem e teoria da mente.

Uma tendência atual deste campo de estudos tem sido a de se tentar identificar variáveis que possam afetar o desempenho das crianças em tarefas de crença falsa. Como foi possível observar, a utilização de termos explícitos denotando crença falsa, presentes em algumas línguas, mas não em outras, produz um efeito local no desempenho das crianças 
nesse tipo de tarefa (Lee et al., 1999; Shatz et al., 2003). Alguns outros estudos também já demonstraram que pequenas mudanças lingüísticas podem promover um melhor desempenho na tarefa, por exemplo, utilizar a palavra primeiro na pergunta utilizada na tarefa de deslocamento de objeto "Aonde ele irá procurar (primeiro) pelo objeto?" (Siegal \& Beattie, 1991). Há, inclusive, um trabalho com crianças falantes do português (Lourenço, 1992, citado por Jou \& Sperb, 2004) sugerindo que o desempenho das crianças mais novas pode ser significativamente melhor com pequenas variações na linguagem utilizada nessas tarefas. O que permanece problemático, no entanto, é que ainda não há nenhuma evidência de que determinados grupos lingüísticos adquirem uma teoria da mente plena mais cedo no desenvolvimento, ou de que determinadas diferenças lingüísticas são responsáveis por diferenças no período de aquisição de uma teoria da mente. Talvez a criação de novas medidas de avaliação da teoria da mente, não restritas à capacidade de compreensão da crença falsa, possa contribuir nessa direção.

Pesquisas com crianças brasileiras, por sua vez, também podem trazer importantes contribuições. Além disso, ainda há muito a ser revelado sobre o processo de desenvolvimento da teoria da mente em crianças brasileiras. Apesar da indiscutível contribuição da pesquisa existente, a realização de mais estudos empíricos se tornou imprescindível. Um possível caminho a ser seguido é o de se investigar a aquisição de palavras que se referem a estados mentais em crianças brasileiras. O estudo de Bartsch e Wellman (1995) revelou que esses termos começam a aparecer no vocabulário de crianças americanas entre 2 e 3 anos de idade. Mas quando palavras como saber e pensar surgem no vocabulário das crianças brasileiras? Uma diferença interessante entre o inglês e o português é a de que a palavra know pode ser traduzida tanto por saber (como em "Eu sei ler") como por conhecer ("Eu conheço Joana"); e o termo think pode ser traduzido tanto por pensar ("Em que você está pensando agora?") como por achar ("Eu acho que vai chover hoje"). Uma possibilidade é a de que o desenvolvimento de uma compreensão de estados mentais, e, possivelmente, de uma teoria da mente em crianças brasileiras seja afetado por essa característica da língua portuguesa: possuir dois termos distintos para marcar dois diferentes usos do think e do know.

É importante observar também que a relação entre linguagem e teoria da mente remete-nos a uma outra questão, a da relação entre linguagem e cognição. Pesquisadores interessados no desenvolvimento cognitivo e lingüístico têm se dedicado nos últimos anos a investigar essa relação. Uma das várias linhas seguidas por estes pesquisadores deriva da hipótese de Sapir-Whorf, ou seja, a idéia de que cada língua, pertencente a uma determinada cultura, molda a forma como membros de sua cultura e comunidade lingüística interpretam o mundo (Whorf, 1956). A hipótese de Sapir-Whorf tem, na verdade, enfrentado oposição nos últimos anos (Lakoff, 1987), mas a questão da relação entre linguagem e pensamento parece ter ressurgido recentemente e têm gerado um número grande de pesquisas e proporcionado importantes evidências (Gentner \& Goldin-Meadow, 2003). Conseqüentemente, estudos investigando possíveis relações entre linguagem e teoria da mente só têm a acrescentar ao conhecimento atual e podem vir a ajudar os pesquisadores na busca por respostas. $\mathrm{O}$ caminho a ser seguido pode se mostrar longo, mas há de trazer grandes frutos para a pesquisa em psicologia do desenvolvimento brasileira e mundial.

\section{Referências}

Astington, J. W., (2001). The future of theory-of-mind research: Understanding motivational states, the role of language, and real-world consequences. Child Development, 72, 685-687.

Astington, J. W., \& Baird, J. A. (Eds.). (2005). Why language matters for theory of mind. New York: Oxford University Press.

Astington, J. W., \& Gopnik, A. (1991). Theoretical explanations of children's understanding of the mind. British Journal of Developmental Psychology, 9, 7-31.

Astington, J. W., Harris, P. L., \& Olson, D. R. (Eds.). (1988). Developing theories of mind. New York: Cambridge University Press.

Astington, J. W., \& Jenkins, J. M. (1999). A longitudinal study of the relation between language and theory-of-mind development. Developmental Psychology, 35, 1311-1320.

Baron-Cohen, S., Leslie, A., \& Frith, U. (1985). Does the autistic child have a "theory of mind"? Cognition, 21, 37-46.

Bartsch, K., \& Wellman, H. (1995). Children Talk about the mind. New York: Oxford University Press.

Bassano, D. (1985) Five-year-olds' understanding of 'savoir' and 'croire.' Journal of Child Language, 12, 417-432.

Cicchetti, D., Rogsch, F., Maughan, A., Toth, S. L., \& Bruce, J. (2003). False belief understanding in maltreated children. Development and Psychopathology, 15, 1067-1091.

Cutting, A. L., \& Dunn, J. (1999). Theory of mind, emotion understanding, language, and family background: Individual differences and interrelations. Child Development, 70, 853-865.

de Villiers, J. G., \& de Villiers, P. A. (2000). Linguistic determinism and the understanding of false beliefs. In P. Mitchell \& K. J Riggs (Eds.), Children's reasoning and the mind (pp. 189-226). Hove, UK: Psychology Press.

de Villiers, J. G., \&. de Villiers, P. A. (2003). Language for thought: Coming to understand false beliefs. In D. Gentner \& S. GoldinMeadow (Eds.), Language in Mind (pp. 335-384). Cambridge, MA: MIT Press.

Dias, M. G. B. B. (1993). O desenvolvimento do conhecimento da criança sobre a mente. Psicologia: Teoria e Pesquisa, 9, 587-600.

Dunn, J., Brown, J., \& Beardsall, L. (1991). Family talk about feeling states and children's later understanding of other's emotions. Developmental Psychology, 27, 448-455.

Farrar, M., \& L. Maag (2002). Early language development and the emergence of a theory of mind. First Language, 22, 197-213.

Flavell, J. H., Flavell, E. R., \& Green, F. L. (1983). Development of the appearance-reality distinction. Cognitive Psychology, 15, 95-120.

Frye, D., \& Moore, C. (1991). Children's Theories of Mind:Mental states and social understanding. Hillsdale, NJ: Erlbaum.

Gentner, D., \& Goldin-Meadow, S. (Eds.). (2003). Language in Mind: Advances in the study of language and thought. Cambridge, MA: MIT Press. 
Gopnik, A., \& Astington, J. W. (1988). Children's understanding of representational change and its relation to the understanding of false belief and the appearance-reality distinction. Child Development, 59, 26-37.

Happé, F. (1995). The role of age and verbal ability in the theory of mind task performance of subjects with autism. Child Development, 66, 843-855.

Jenkins, J. M., \& Astington, J. W. (1996). Cognitive factors and family structure associated with theory of mind development in young children. Developmental Psychology, 32, 70-78.

Jou, G. I., \& Sperb, T. M. (2004). O contexto experimental e a teoria da mente. Psicologia Reflexão e Crítica, 17(2), 167-176.

Lakoff, G. (1987). Women, Fire and Dangerous Things. Chicago: University of Chicago Press.

Lee, K., Olson, D., \& Torrance, N. (1999). Chinese children's understanding of false Beliefs: The role of language. Journal of Child Language, 26, 1-21.

Moore, C., Pure, K., \& Furrow, D. (1990). Children's understanding of the modal expression of speaker certainty and uncertainty and its relation to the development of a representational theory of mind. Child Development, 61, 722-730.

Perner, J., Leekam, S., \& Wimmer, H. (1987). Three-year-olds' difficulty with false belief: The case for a conceptual deficit. British Journal of Developmental Psychology, 5, 125-137.

Peterson, C. C., \& Siegal, M. (1998). Changing focus on the representational mind: Deaf, autistic and normal children's concepts of false photos, false drawings and false beliefs. British Journal of Developmental Psychology, 16, 301-320.
Roazzi, A., \& Santana, S. M. (1999). Teoria da mente: Efeito da idade, do sexo e do uso de atores animados e inanimados na inferência de estados mentais. Psicologia: Teoria e Pesquisa, 12, 1-17.

Shatz, M. (1994). Theory of mind and the development of social-linguistic intelligence in early childhood. In C. Lewis \& P. Mitchell (Eds.), Children's early understanding of mind: Origins and development (pp. 311-329). Hillsdale, NJ: Erlbaum.

Shatz, M., Diesendruck, G., Martinez-Beck, I., \& Akar, D. (2003). The influence of language and socioeconomic status on children's understanding of false-belief. Developmental Psychology, 39, 717-729.

Siegal, M., \& Beattie, K. (1991). Where to look first for children's knowledge of false beliefs. Cognition, 38, 1-12.

Wellman, H. M. (1990). The child's theory of mind. Cambridge, MA: Bradford Books.

Whorf, B. (1956). Language, thought and reality: Selected readings of Benjamin Lee Whorf. (J. B. Carroll, Ed.). Cambridge, MA: MIT Press.

Wimmer, H., \& Perner, J. (1983). Beliefs about beliefs: Representation and constraining function of wrong beliefs in young children's understanding of deception. Cognition, 13, 103-128. 